\title{
¿En qué lengua predicar en Cataluña? La polémica de los memoriales de 1636
}

\author{
What language should be used for predication in Catalonia? \\ The pamphlet controversy of 1636 \\ Matthias Gloël \\ Universidad Católica de Temuco-CHILE \\ mgloel@uct.cl
}

\section{Resumen}

El objetivo de este artículo es analizar la polémica lingüística de 1636 entre Alexandre Ros y Dídac Cisteller en tres contextos: en el lingüístico-eclesiástico, en el sociolingüístico y también en el socio-político, para comprender las diversas dimensiones que tenía la cuestión acerca de en qué lengua había que predicar en la Cataluña del siglo XVII. A continuación se analizan los argumentos de ambos autores, haciendo un enfoque en similitudes y diferencias en vez de simplemente asumir que se trata de posiciones completamente opuestas. Combinando los tres contextos referidos con la argumentación de los autores se concluye que no se trata netamente de una cuestión lingüística sino que las posiciones y los argumentos expuestos por ambos autores representan los intereses de distintos grupos de poder, cuya posición se ve favorecida en un contexto u otro.

Palabras clave: historia moderna, historia de Cataluña, sociolingüística histórica, lengua de predicación

\begin{abstract}
The purpose of this article is to analyze the linguistic debate in 1636 between Alexandre Ros and Dídac Cisteller in three contexts: the linguistic ecclesiastical one, the sociolinguistic one and also in the sociopolitical one, in order to understand the different dimensions of the question in which language had to be prayed in the 17th century Catalonia. After that we analyze the different arguments from both authors, with an approach of dividing them into similar and different, rather than simply to assume that their positions were completely opposed. By combining the three contexts we mentioned with the author's arguments we conclude that the debate is not a pure linguistic question, but that the positions and the arguments of both authors represent the interests of different groups of power, who's position would be favored by one or the other context.
\end{abstract}

Matthias Gloël

¿En qué lengua predicar en Cataluña? La polémica de los memoriales de 1636.

Autoctonía. Revista de Ciencias Sociales e Historia, Vol. IV, N 1 , Enero-Junio 2020, 28-43

ISSN 0719-8213

DOI: http://dx.doi.org/10.23854/autoc.v4il.151 
Keywords: early modern history, history of Catalonia, historical sociolinguistics, language of predication

Recibido: 01 de Junio de 2019 - Aceptado: 30 de Septiembre de 2019

\section{Introducción}

La polémica entre Alexandre Ros ${ }^{1}$ (Memorial en defensa de la lengua castellana, para que se predique en ella en Cataluña) y Dídac Cisteller (Memorial en defensa de la lengua catalana para que se predique en ella en Cataluña) acerca de la lengua en la cual habría que predicar en Cataluña (1636)ya ha sido objeto de estudio previamente. Ambos memoriales se publicaron en $1636^{2}$. En una obra más reciente, Modest Prats reproduce los textos íntegros en su obra Política lingüística de l'Església catalana, que abarca principalmente los siglos XVI y XVII. Incluye, además, un tercer memorial anónimo que repite básicamente los argumentos de Ros a favor del castellano. Sin embargo, en su breve introducción a los memoriales solamente los contextualiza dentro del debate lingüístico de los concilios tarraconenses de 1636 y 1637. Principalmente valora las dotes retóricas de ambos autores, señalando que la argumentación de Ros es más elaborada, en resumen superior, a la de Cisteller (Prats, 1995: 23). Si bien se trata en este caso de un motivo y una ocasión particular para el debate lingüístico, autores como Xavier Baró i Queralt (2009: 79-87) Sílvia Canalda junto a Cristina Fontcuberta (2012) han mostrado que los textos también forman parte de un debate más largo que hubo en la Cataluña moderna acerca de la cuestión de la lengua.
Antoni Simon i Tarrés toca el tema lateralmente en su gran obra sobre Els orígens ideològics de la revolució catalana de 1640 (1999) y nuevamente en Llengua i política a la Catalunya del segle XVII (2016) que en el fondo, y así lo revela el subtítulo Alexandre RosiGomar (1604-1656), es una biografía precisamente de Alexandre Ros. Por ello, Simon i Tarrés analiza la obra sobre todo en el contexto de la vida del jesuita. Igualmente enfocado en la figura de Ros es el reciente artículo de Enric Querol Coll, intitulado Alexandre Ros. Política, llengua i literatura a la Catalunya barroca que también ubica el memorial dentro de la trayectoria íntegra del autor.

Los enfoques desde la historiografía sobre estos dos autores rompieron en cierta manera con el monopolio de los lingüistas (Prats, 1989; Torrent, 1989; Pitarch, 2000; Marfany, 2001: 211-286) que ya se ocuparon antes de estos memoriales en el contexto de la historia de la lengua. Existe, sin duda, el peligro de proyectar conceptos y mentalidades posteriores a épocas anteriores, más aún si el acercamiento tiene lugar desde otra disciplina. Así, para la época que nos ocupa, Clare Mar-Molinero relaciona la cuestión de la lengua con los intento de política centralizadora del conde-duque de Olivares, privado de Felipe IV: "Clearly, a major obstacle in any such centralizing policy would be the existence of different vernaculars, linked with diverse identities. The need for one 'national' language was hence placed on 
the political agenda" (Mar-Molinero, 2000: 86). En realidad, a Olivares le preocupaba poco o nada la diversidad lingüística de la monarquía (Milhou, 1995: 30) ni representaba un nacionalismo castellano o incluso español, sino que el fin de aplicar el sistema fiscal y administrativo castellano a los demás territorios era el de aumentar el poder real en aquellos territorios (Mond, 1996: 11).

Tampoco parece adecuada la afirmación de Prats (1995: 37) de que la Cataluña (y también la del Reino de Valencia) del siglo XVII atravesaban por un proceso de sustitución lingüística, añadiendo la pregunta de "per què no el viu Portugal, que l'any 1637 es trobava en una situació pràcticament igual a la nostra”. Joan-Lluís Mafany (2008: 102) ha señalado que no le parece apropiado hablar de sustitución lingüística para la edad moderna, sino de una situación de diglosia de clase, ya que "a les societats d'Antic Règim la pràctica lingüística està completament i expressament condicionada per la classe". Con todo, a nivel popular no hay ni siquiera una diglosia y mucho menos una sustitución de la lengua. La diglosia existe solamente a nivel de élites y ello sí se asemeja mucho al Portugal de aquella época, donde también las élites sociales e intelectuales dominaban todos el castellano, una situación que solo cambiaría hacia fines del siglo XVII e inicios del XVIII (Teruelo Núñez, 1987: 319).

Con todo, conviene interpretar los manifiestos de Alexandre Ros y Dídac Cisteller en tres contextos: el lingüístico-eclesiástico, el sociolingüístico y también en el socio-político para comprender las diversas dimensiones que tenía la cuestión acerca de en qué lengua había que predicar en la Cataluña del siglo XVII. A continuación de ello, se hará un análisis del uso del idioma en ambos memoriales y se realizará una comparación entre ambos.

\section{Contexto sociolingüístico}

Desde el siglo XV, el castellano empezaba a ganar terreno en los reinos fuera de la corona de Castilla, haciéndose su uso más habitual entre las élites. El desarrollo en los distintos reinos fue ciertamente desigual. En Aragón, donde la lengua propia nunca se elevó como lengua literaria se estima que alrededor de 1500 las elites urbanas en Aragón ya se encontraban castellanizadas (Nagore, 1977: 14). Distinta fue la situación en el Reino de Valencia y Cataluña donde sí se escribía en catalán desde la edad media. Antoni Badia i Margarit (1999: 32) señala que hasta fines del siglo XV el castellano y el catalán estuvieron en un nivel parejo. Después, sin embargo, continúa el autor, habría que asumir una "superioridad del castellano sobre el catalán”. La aceptación del castellano se produjo más rápidamente y en mayor grado en Valencia, sobre todo después de la rebelión de las Germanías (1520-1522) cuando los nobles vencedores para distinguirse de los agermanados adoptaron la lengua del rey que les había apoyado (Carbonell, 1979: 93). También en Portugal el castellano gana influencia a lo largo del siglo XV. El ejemplo más emblemático del siglo XV y principios del XVI es el dramaturgo Gil Vicente. De sus 46 obras de teatro escribió unas 11 en castellano y otras 19 bilingüe. No obstante, tanto el catalán como el portugués seguían vivos, también como lenguas literarias como muestran numerosas publicaciones en ambos idiomas durante los siglos XVI y XVII. Con todo, es necesario señalar que se trata de un fenómeno 
limitado a la nobleza y las élites urbanas, sin que afectara apenas a los demás grupos sociales, tal como evidencia Manuel Peña Díaz (1997) para el caso catalán.

La superioridad del castellano es aceptada implícitamente por muchos autores en Valencia, Cataluña y Portugal pero rara vez de forma explícita. Ocurre en muchos textos que autores de estos territorios alaban a su lengua escribiendo en castellano, negando cualquier inferioridad a pesar de no emplearla en su texto. La justificación formal del uso del castellano suele ser su mayor extensión y que así más personas podrían leer las obras pero en el fondo esto no es nada más que un reconocimiento de la lengua del prestigio (Pas, 1579; Beuter, 1546; Sousa de Macedo, 1631).

\section{Contexto lingüístico-eclesiástico}

El latín había dejado de ser la lengua del pueblo desde hacía mucho tiempo y en la práctica se solía predicar en lengua vulgar ya desde la Alta Edad Media. Tras el concilio de Trento (1545-1563) la iglesia se tuvo que adaptar a la fragmentación lingüística en Europa (Baggioni, 1997: 103). El concilio precisamente decretó, si bien quedaba prohibido traducir la Biblia, que debía predicar en la lengua que el pueblo podía entender.

Para aplicar los decretos de Trento se dispuso que se unieran los concilios provinciales en un plazo no mayor de un año. Como es sabido, las provincias eclesiásticas habitualmente no coincidían con las políticas. Por ejemplo, la Tarraconense, aparte de Cataluña también abarcaba diócesis de Navarra, Aragón, Valencia y Mallorca (Agustí, 1994: 47).
En dicha provincia ya existía una larga tradición conciliar y ésta fue usada para implementar las reformas tridentinas, celebrando nueve concilios entre 1567 y 1598 y, a continuación, uno aproximadamente cada cinco años hasta 1757 (Fernández Terricabras, 2011: 230; ver también Fernández Terricabras, 2010). En estos concilios se insistía repetidamente en la obligación de emplear el catalán en la predicación en Cataluña. Por ejemplo, en 1591 el arzobispo de Tarragona Joan Terés ordena que se haga un breve compendio en lengua catalana del catecismo romano para toda la provincia (Agustí, 1993: 84).

El hecho de que en el concilio de 1636 se continuara debatiendo el tema de la lengua de predicación indica que a pesar de las disposiciones hechas en concilios previos a favor del catalán, esto no se había cumplido en la práctica. De hecho, todavía en el concilio de 1685 se insistiría en la necesidad de predicar en la lengua vernácula de Cataluña (Agustí, 1993: 74). Se denunciaba sobre todo a los jesuitas que ignorasen las disposiciones del concilio provincial predicando en castellano (Prats, 1995: 19). Efectivamente, la orden jesuita optó pronto por el uso del castellano en la educación y predicación y contribuyó así a la difusión del castellano entre las élites (Morgado García, 2007: 91). Para el caso catalán específicamente, Ignacio Vila Despujol (2012) ha evidenciado además la cercanía y colaboración mutua entre la Compañía de Jesús y los virreyes de Cataluña, en su gran mayoría nobles castellanos. Ciertamente, cabe señalar que hubo excepcione como el caso de Pere Gil (1551-1622), cronista y teólogo que fue uno de los pocos jesuitas que principalmente publicaban en catalán. Además, es necesario tener en cuenta 
la evolución lingüística a largo plazo. El61,9\% de los impresos jesuitas en Cataluña en el siglo XVI está en castellano $(4,76 \%$ en catalán, $33,33 \%$ en latín), porcentaje que en el siglo XVII aumenta a 83,61\% (7,98\% en catalán, 8,4\% en latín) (Betrán y Blanco Fernández, 2012: 573).

Un año antes del concilio, en el sínodo de Urgell se había señalado la poca utilidad que tiene el predicar en castellano en Cataluña: "Atenent i considerant los inconvenients grans i poc profit per a l'ànima se segueixen del predicar en llengua castellana, per no entendre aquella la major part de la gent, per ésser plebeia". Por ello, se insiste que "no es predique sinó en llengua catalana" (Prats, 1995: 72). Cabe señalar que el decreto tridentino de predicar en lengua vernácula se acepta por prácticamente todos los prelados en Cataluña, el desacuerdo radica en cuál lengua vernácula se debería predicar. En el concilio de 1636, finalmente, se aprobó una constitución que prohibía a todos los predicadores, independientemente de su origen, de usar otro idioma que no fuese el catalán. Nunca una disposición de un concilio tarraconense había sido tan rigurosa en cuanto a la lengua de predicación y con ella el uso del castellano se hacía imposible, cosa que provocó mucha polémica, también fuera del concilio, como es el caso de nuestros dos memorialistas, Alexandre Ros y Dídac Cisteller (Prats, 1995: 23). De hecho, el propio concilio de Trento, apunta Agustí (1993: 61), "més aviat incita que mana. El discurs dels concilis catalans és més clarament imperatiu".

Con todo, es necesario puntualizar que no se trata de una polémica entre castellanos y catalanes con cada grupo defendiendo el uso de su propia lengua (Fernández Cañueto, 2016: 55). A modo de ejemplo, por una parte, el propio Alexandre Ros cuyo memorial defendía la predicación en castellano era catalán, proveniente de la provincia de Lleida, donde nació en 1604. Por otra parte, el que inició el debate conciliar que terminaría llevando a estas disposiciones tan drásticas contra la predicación en castellano, era precisamente el obispo de Tortosa, Justino Antonílez de Burgos y de Saavedra, oriundo de Valladolid. Dicho arzobispo redactó un memorial para tal fin, en el cual señala “cuán poco se ajustan [los predicadores] al capítulo y modo de entender de todo el pueblo de Catalunya los que predican en lengua castellana, y por consiguiente cuánto se apartan de la mente de los Concilios". La predicación en castellano no tendría mucha utilidad, ya que "son muchíssimos en cada pueblo de Catalunya los que ni hablan ni entienden el castellano" (Prats, 1995: 78)33. Este obispo pertenecía a la orden agustina, lo cual también podría hacer que se inclinara hacia una posición opuesta a la de los jesuitas, los cuales eran los que con más énfasis defendían la predicación en castellano.

\section{Contexto socio-político}

Como es sabido, Cataluña era parte de la corona de Aragón (Belenguer, 2001; Sabaté, 2017), que a su vez formaba parte de la monarquía compuesta o policéntrica de los Habsburgo (Elliott, 1992; Cardim et al., 2012; Rivero Rodríguez, 2017). El rey era señor de una serie de territorios, cada uno con una realidad foral y jurídica distinta. Dada la extensión de la monarquía no era posible que el rey estuviese presente personalmente en cada uno de 
ellos, asunto muy grave en aquella época, ya que se creía que con el rey ausente peligraba el buen gobierno (Pérez Samper, 1999: 115). La solución fueron los virreyes que como representantes de la persona del monarca (alter ego) gobernaban a los reinos peninsulares, italianos y americanos donde el rey no residía personalmente (Rivero Rodríguez, 2011; Cardim y Palos, 2012).

La mayoría de los cargos importantes de la monarquía fue ocupada, si bien no exclusivamente, por la alta nobleza castellana. También fue así en caso del cargo de virrey en el cual abundan nobles castellanos a la vez que hubo apenas catalanes que desempeñaron esta función en su propio territorio. En cuanto a los obispos, según Joan Bada (1982), entre 1563 y 1640 el 41,6\% de ellos eran catalanes. Joan Busquets i Dalmau realiza un cómputo solo del siglo XVII y señala que de los 119 obispos nombrados 56 (47\%) eran catalanes. Sin embargo, apenas hubo catalanes en los importantes obispados de Tortosa y sobre todo Tarragona (arzobispado) mientras que el mayor porcentaje de obispos catalanes se encuentra en Girona y Vic (Busquets i Dalmau, 1994: 477-478). La carrera eclesiástica era a menudo emprendida por hijos menores de la nobleza y efectivamente mucha nobleza segundona ocupaba obispados en los territorios de la monarquía. En el momento concreto de la publicación de nuestros memoriales el número de obispos catalanes era precisamente muy bajo. En el concilio de 1637 que en realidad fue la continuación del anterior de 1636, Pau Duran, obispo de Urgell, era el único catalán que participaba (Prats, 1995: 32).

\section{Los memoriales y su idioma}

El primero de los dos manifiestos, el de Alexandre Ros a favor de la predicación en castellano, no lleva fecha pero podemos ubicarlo sin problemas en el año 1636, ya que, por una parte, hace referencia a la iniciativa conciliar (probablemente se refiere a la propuesta del obispo de Tortosa) de prohibir la predicación en castellano y, por otra parte, el segundo manifiesto que constituye una respuesta al primero, sílleva fecha de impresión del año 1636. Señala Ros que dicha iniciativa le ha motivado a redactar su memorial para mostrar "algunos inconvenientes que parecen sustanciales para que no se cierre del todo la puerta a una cosa, cuyo uso es tan provechoso, y necessario"4.

A su vez, Dídac Cisteller justifica la redacción de su memorial con la aparición del primero: “Llegó a mis manos un memorial en ofensa de la lengua catalana, cuyo autor trata de desacreditalla con el mundo". En consecuencia, el suyo "contiene las conveniencias que ay se predique en Cataluña en su lenguage, deshaze las del papel contrario"5.

Como se puede apreciar, ambos memoriales están escritos en castellano, lo cual en el caso de Ros no sorprende pero sí podría resultar extraño que Cisteller escriba su defensa del catalán en castellano. Sin embargo, la alabanza de una lengua realizada en otra (la castellana) era algo bastante común en los reinos no castellanos. Así, por ejemplo, enaltecen Martí de Viciana (1574) y Gaspar Escolano (1610: 88-97) la lengua valenciana en sus obras que están escritas en castellano. Los autores suelen emplear el término "lengua valenciana", lo cual no implica que la consideren una lengua 
distinta al catalán sino que son conscientes de que son variantes de la misma. Sin embargo, Escolano afirma que la evolución de ambas variantes habría sido muy distinta. Mientras el catalán habría permanecido "montarazy mal sonante", el valenciano se habría convertido en una de las lenguas "mas dulces, y graciosas" del mundo (Escolano, 1610: 93). También el portugués António de Sousa de Macedo (1631: 234v.241) elabora en castellano una serie de criterios para mostrar que la lengua portuguesa es la más digna del mundo. Así mismo, en la Cataluña del siglo XVII, muchos escritos en alabanza o glorificación de Cataluña o su lengua estaban escritos en castellano (Simon i Tarrés, 1999: 106).

La muy acertada conclusión que ya han destacado varios autores es que la lengua en la Edad Moderna no tiene el papel cohesionador para la identidad de una nación, que sí tendría en el siglo XIX en adelante (Burke, 2006: 73; Simon i Tarrés, 2016: $15)^{6}$. Lo anterior no significa que la cuestión lingüística fuese algo completamente neutro. Sobre todo en Cataluña y Portugal existían debates muy vivos acerca de en qué lengua se debería publicar, justificando algunos su elección del castellano y otros su apuesta por el catalán o portugués respectivamente (Gloël, 2014: 219-232).

La lengua constituye un valor o una excelencia relacionada con un territorio, al igual que otros factores históricos o geográficos, por ejemplo. El mayor o menor grado de estas excelencias definían la dignidad de un territorio. Se trata de lo que Simon i Tarrés (2005: 105) ha llamado "batalles preeminencials" que se llevaban a cabo a través de escritos como crónicas, relaciones geográficas o también tratados lingüísticos. Sin embargo, la dignidad de la lengua no disminuía por el hecho de que un autor la alabara usando otro idioma, algo muy frecuente en la península fuera de Castilla.

\section{Los dos memoriales en comparación: puntos en común y oposiciones}

Ambos memorialistas emplean el mismo estilo recogiendo los argumentos del texto que pretenden refutar. Así señala Ros (1636) al inicio de su texto: "Para proceder con mas claridad, intento desarmar una a una, las razones que pone en el memorial, en que pretende lo contrario, el señor Obispo de Tortosa”. Cisteller (1636), por su parte, introduce de esta forma a su memorial: "Responde el Doctor Adrin en su papel, a otro del Illustrissimo Señor Don Iustino Antonilez Obispo de Tortosa, exemplar de santos Prelados, que con Christianissimo zelo de las almas propuso, y obtuvo en el Sacro Concilio Tarraconense, que la predicacion en el Principado de Cataluña fuesse en su lengua materna por las razones que en su papel alegò, estas pretende deshazer el Doctor Adrin en su informe: en este es mi intento mostrar al mundo que no lo ha hecho". Efectivamente, mientras Ros siempre expone el argumento del obispo para después contradecirlo, Cisteller, expone el mismo argumento del obispo, el rechazo de Ros y su propia contraria. Cabe señalar que esta forma de desarrollar la argumentación a través de un texto contrario era muy frecuente en aquella época y se encuentra especialmente a menudo en panfletos o memoriales en el contexto de las rebeliones de Cataluña y Portugal en la década de los 1640. 
Hay varios puntos temáticos que a primera vista muestran un acuerdo de fondo entre ambos autores pero que se convierte en desacuerdo al hacerse más concreto y a la hora de interpretar los hechos. Tanto Ros como Cisteller afirman que hay una presencia del idioma castellano en Cataluña y que esta presencia se halla estrictamente en un contexto urbano. Por ello, Ros (1636) empieza su texto afirmando que "en las Villas, y Lugares de Cataluña, es justo, y aun necessario, que se predique en vulgar Catalan”. En las ciudades, en cambio, la cosa muy distinta. Si bien admite que para los pocos en las ciudades que no entienden el castellano debería haber una o más iglesias. En general, sin embargo, "bastantemente queda provado, que es ya comun en las mas Ciudades de Cataluña el Castellano". En otra parte del texto también da una explicación de cómo se ha dado esta situación: en Barcelona y también en las otras ciudades el castellano estaría muy presente, por “ò el ser passo de Castilla, ò por el concurso de estudiantes extrangeros, ha de aver quien se cultive" (Ros: 1636).

Cisteller toma este argumento y lo admite únicamente y solo hasta cierto punto para Barcelona y que como es "escala de Italia, y Emporio de naciones estrangeras" se podría debatir acerca de una predicación en castellano. Continúa el autor que nada de esto se puede aceptar para el resto de Cataluña: en Tortosa, Girona o Lleida en todo el año solo habría dos o tres días que la gente vería un castellano. En otras ciudades todavía más pequeñas, como Manresa, Solsona, Vic o Urgell, "si ven algun castellano es por milagro" (Cisteller: 1636). En resumen, Cisteller acusa a Ros aplicando las condiciones de Barcelona a todas las demás ciudades de Cataluña y por ello llegar a conclusiones tan erróneas.

Que el dominio del castellano es Cataluña sea además un fenómeno de clase queda en evidencia de forma mucho más clara en Cisteller que en Ros. Como Ros quiere mostrar que la presencia del castellano en las ciudades es amplia, necesariamente esta presencia tiene que abarcar a más personas que las élites urbanas. Señala en este sentido que es probable que se entienda el castellano comúnmente en Cataluña, "donde todos los libros que se imprimen son en esta lengua" (Ros: 1636). A esto le responde Cisteller que los libros estarían únicamente "en manos de gente entendida" pero no en las de la plebe. Entonces, para Cisteller el hecho de entender el castellano va de la mano con el ser letrado, lo cual implica a la vez que la gran mayoría de los catalanes no lo entendería, incluida la gente de Barcelona.

Ros, en cambio, insiste repetidamente que la comprensión del castellano es un fenómeno más amplio. Por un lado, argumenta que de no ser así no habría obispos y vicarios generales provenientes de Castilla y Aragón, "porque la muger, y el rudo, que han de tratar en sus Tribunales, quedaran sin consuelo, y no es assi, porque el vulgo entiende a su Prelado y a sus Ministros estrangeros". Por otro lado, aporta también ejemplos de la vida más bien cotidiana: "Los oficiales entienden a los Castellanos, quando mercan algo en sus tiendas, y no dudo que si les dizen alguna injuria, se indignan, que es señal, que entienden comunmente los plebeyos esta lengua" (Ros: 1636). 
Con todo, tanto Ros como Cisteller comparten el punto de vista que debe haber predicaciones distintas para doctos y para vulgos, para usar los términos empleados por los autores. Pide Ros la posibilidad de predicar a los doctos en castellano, ya que "no es justo manejar un mismo lenguaje para sabios, è ignorantes". Lo anterior implica, además, una división entre una lengua castellana apta para gente culta y otra catalana para los plebeyos. Cisteller (1636) confirma esta visión afirmando que "puede tal vez el Predicador en el retiro de una escuela donde no acude vulgo, sino gente dota, y entendida florearse en el estilo, y predicar en Castellano si se entiende".

Esta visión corresponde a una más general de aquella época que atribuía distintos grados de dignidad a las lenguas según las posibilidades de usarlas en todos los contextos y ámbitos. Por ejemplo, el ya mencionado Sousa de Macedo (1631: $236 \mathrm{v}$.) define cinco calidades para la lengua perfecta: ser copiosa de palabras, buena de pronunciar, breve en el decir, que escriba lo que dice y que sea apta para todos los estilos. Sobre todo en Castilla se compartía la visión, expresada, por ejemplo, por autores como Bernardo Alderete o Damasio de Frías, que el castellano era la lengua española más digna y muy por encima de otras como el catalán, el portugués o el vasco (Gloël, 2014: 201203). A esto le contesta en el contex to del concilio de 1636 el obispo de Urgell Pau Duran que la lengua catalana es suficientemente apta para todas las funciones y al ser además la natural la más indicada para la predicación (Agustí, 1993: 69).

Sin embargo, esta visión castellana hacia las lenguas españolas es compartida también en parte (si bien no por todos) por letrados en el resto de la península y Cisteller parece ser uno de ellos también. De hecho, usa la mayor dignidad del castellano para reforzar su argumentación señalando que al pueblo le sería de por sí más difícil entender un sermón en castellano que en cualquier variación del catalán, "porque en el Castellano ay dos cosas, lo exquisito de los vocablos, y la phrasi, y la estrañeza de la lengua, que no milita n nuestro Catalan" (Cisteller, 1636). Según Ros, la lengua castellana es "copiosa, y substancial, facil a qualquier cultivo, y muy ajustada para hombres juiziosos". Agrega a continuación que "las letras son sombras del Imperio, allí florecen, donde estos mandan y la lengua de la Monarquia, siempre ha sido respetosa a los hombres de caudal" (Ros: 1636). También el obispo de Tortosa que con su memorial a favor del catalán había iniciado toda la polémica, había reconocido la superioridad del castellano: “Ha s'entrat, amb no poc dany, per tota Catalunya el predicar en la lengua castellana, que si bé més copiosa, mes no ben entesa ni natural". Insiste, además, en el aspecto pragmático de la predicación: "No és la predicació per a donar gust amb la consonància del llenguatge ni per a mirar al delit dels oients; no és per a sols los doctes, antes per a persuadir i moure per a la virtut i ensenyar los més ignorants" (Prats, 1995: 75-76).

En este punto conecta Ros (1636) la dignidad del castellano con el hecho de ser la lengua de la monarquía: "no se estorva la justa estimacion, que devemos hazer de la lengua Castellana, por sus dulçuras, y agrados, y por ser el idioma comun de la Monarquia de España". Ambos autores coinciden en este punto, que el castellano es la lengua de la monarquía pero de nuevo lo interpreten 
de otra forma. Afirma Ros (1636) que por ello solo se debería predicar en castellano pero no en otras lenguas de gente que podría peregrinar por Cataluña, ya que "la Castellana es lengua del Imperio, y como generalmente se entiende, se le deve esse respeto". En este contexto explica Ros que en el caso ideal según él toda la predicación se debería hacer únicamente en castellano. Con varias referencias eclesiásticas expone que no se debería predicar "en la lengua particular de las Provincias, sino en la comun, que avemos dicho". Establece una comparación con Italia donde hay que predicar "en la lengua comun, que es la Toscana". La conclusión de Ros (1636) es que "segun esto, no se devia predicar en Cataluña, sino en la lengua comun, que es la Castellana". Pero como eso por el momento no le parece realista de conseguir, se conformaría con que no se prohíba y se posibilite la predicación en ella. Sin embargo, en la parte final, enfatiza la singularidad del caso catalán: "La lengua Castellana se estima en todo el mundo, la leen publicamente en Francia, Italia, Flandes y Alemaña, y sola Cataluña, nobilissimo miembro de esta Monarquia, ha de despreciar lo que todo el mundo estima" (Ros: 1636).

Cisteller, por su parte, no niega que el castellano sea la lengua del imperio o de la monarquía, sin embargo, argumenta que no por eso es más entendida en Cataluña. Agrega el autor, además, que esto se puede hacer extensivo a muchas otras partes de la monarquía, ya que "ni en Sicilia, Milan, Flandes, Cerdeña, Portugal, Vizcaya, y Cataluña es entendida la Castellana comunmente". Concluye que por lo tanto, la lengua común debería ser de utilidad en todos los territorios de la monarquía pero "mal lo harà sin ser entendida"
(Cisteller, 1636). También recoge Cisteller (1636) la comparación realizada por Ros con la lengua toscana en Italia, señalando que "la disparidad de Italia a nuestra España es manifiesta porque en Italia toda se entiende el Toscano aun del pueblo" (afirmación, por cierto, lejos de la realidad), cosa que "no corre en la Castellana en todos los miembros de España".

Otro argumento que pone Ros sobre la mesa es que el castellano habría sido la lengua de Santiago, patrón de España en ella habría realizado la evangelización de le península y, por lo tanto, también en Cataluña: "Pues una lengua, que la trahia consigo, como en deposito, nuestro Patron Santiago; y con que plantò la Fè en España, la avemos de desterrar del Pulpito, aviendo entrado con ella el Evangelio? Y aviendo dexado el tiempo, tantas huellas de que predicò Santiago en Cataluña; porque avemos de cerrar la puerta, a la que traxo a este Principado la luz de nuestra Fè" (Ros, 1636)? Ros (1636) fundamenta esta afirmación con una referencia "al Licenciado Madera, en el libro que haze en defensa del monte Santo, donde prueva, que la lengua en que predicò Santiago, es la misma Española que ahora hablamos".

La obra de Gregorio López Madera, a la cual Ros hace referencia, es intitulada Discursos de la certidumbre de las reliquias descubiertas en Granada desde el año de 1588 hasta el de 1598 (1601). Una parte de ella está dedicada a los orígenes de la lengua castellana. En ella rechaza la teoría que el castellano sea un derivado del latín, pues "que hazen muy mal los que de tal manera quieren hazer à nuestra lengua corrupta de la Latina". En cambio, defiende la teoría que la castellana 
fue una de las 72 lenguas originarias de la confusión de lenguas ocurrida tras la construcción de la torre de Babel (Génesis 11), por lo cual sería la lengua que siempre se ha hablado en España (López Madera, 1601: 65v.70). Esta obra de López Madera forma parte de los denominados "falsos cronicones", con los cuales alrededor de 1600 se intentaban llenar huecos históricos (Hurtado et al., 1940: 712-713).

Estas falsificaciones, si bien tuvieron más seguidores, encontraban oposición incluso dentro de Castilla y Cisteller tampoco las acepta. Afirma que "admiracion mas que ordinaria me causa, que el Dotor Adrin (persona tan juyziosa como en su papel se trasluze, que le admiro y aprecio por erudito) se haya bevido tal cosa". Con referencias a autores castellanos célebres como Luis de Bavia (Historia Pontifical y Católica) y Juan de Mariana (Historia general de España) para afirmar que "al tiempo que Santiago vino a España no havia rastro de la lengua Castellana, porque en ella dominavan los Romanos" y cuya lengua latina además habría estado en su máximo esplendor en aquel momento (Cisteller: 1636).

\section{A modo de conclusión}

Si bien es verdad, como apunta Xavier Torres Sans (2008: 156), que las argumentaciones sobre todo de Cisteller son más que nada pastorales o tridentinas, la polémica no alcanza su verdadero significado si se analiza solo en este contexto. Tampoco se trata de una neta oposición entre catalanes y castellanos, lo cual queda evidenciado ya por el hecho de que es un castellano, el obispo de Tortosa Justino Antonílez de Burgos y de Saavedra, quien en el concilio pide la prohibición de predicar en castellano y es un catalán, Alexandre Ros, quien fervientemente defiende el uso de esta lengua. Tampoco estamos ante un nacionalismo lingüístico, más característico de los siglos XIX y XX. La lengua en el siglo XVII no es un gran factor cohesionador y no supone ninguna contradicción que Dídac Cisteller escriba en castellano su memorial en defensa del uso de la lengua catalana.

Los memoriales, a pesar de sus argumentaciones lingüísticas o pastorales representan intereses políticos de grupos sociales. Como hemos apuntado, la carrera eclesiástica, particularmente los puestos de obispo o arzobispo, eran una salida cotizada por muchos hijos menores de nobles, es decir, los que no podían aspirar a heredar los títulos nobiliarios de su casa. Ahora bien, teniendo en cuenta que especialmente a partir de Felipe II los nobles castellanos dominaban los cargos más importantes de la monarquía en detrimento, entre otros, de la nobleza catalana, esta última debía buscar vías para mejorar sus posibilidades de obtener dichos cargos que les estaban disputando incluso dentro del propio principado. Una de estas vías podía ser imposibilitar la predicación en castellano y con ello evitar el nombramiento de no catalanes para los obispados del principado asegurando de esta forma dichos cargos para la élite eclesiástica. Así, el debate acerca de la predicación y la utilización de una supuesta preocupación por los "vulgos" y que éstos entiendan los sermones, se convierte en un arma política al servicio de distintos grupos privilegiados. Dídac Cisteller como catedrático de leyes en la Universidad de Lleida parece representar estos intereses de los 
grupos privilegiados catalanes aunque ciertamente este personaje merecería una investigación más profunda (como sí existe acerca de Alexandre Ros) que revele sus redes clientelares y sus vínculos con la nobleza catalana. Lo que sí se puede señalar es que el profesorado de leyes de la Universidad de Lleida tenía estrechos vínculos con la oligarquía urbana catalana de la ciudad, ya que varios de ellos paralelamente ocupaban cargos municipales (Ramis Barceló, 2018: 60; ver además los trabajos de Passola i Tejedor, 1986; 2001).

En el mismo contexto hay que entender las defensas del uso del castellano que en el fondo defiende los intereses de la nobleza castellana y también de otros territorios de la monarquía, es decir, de los no catalanes que estaban en condiciones de obtener un cargo eclesiástico en Cataluña. En este sentido, Alexandre Ros defiende estos intereses que son también muy propios de la Compañía de Jesús que se caracteriza por su preferencia de predicar y educar en castellano. También el Colegio de San Martí en Girona del cual provenía Ros tenía una fuerte tradición de publicar en castellano (Prats, 1995: 102). Por lo tanto, Ros ya se formó en esta tradición castellanista, también consecuencia de los fuertes lazos de la compañía con la corona y la nobleza castellana. Cabe añadir, como señala Simon i Tarrés (2016: 103-104), que los jesuitas catalanes de aquel momento eran una de las órdenes religiosas más cercanas a la corona, la cual evidentemente estaba de lado de la nobleza castellana, ya que era la corona que designaba dichos nobles para ser virreyes $u$ obispos en Cataluña.
Por otra parte, esta polémica no forma realmente parte de los debates acerca de la lengua en aquella época. Si bien se defiende su mayor difusión al ser la lengua de la monarquía, ambos autores ambos catalanes, reconocen la superioridad del castellano al afirmar que la gente culta (doctos) deben recibir la predicación en castellano. La diferencia está en que Cisteller solo admite esto en caso de que no haya nadie presente que no entienda el castellano, algo que según el autor rara vez puede ocurrir. Ros, en cambio, defiende que en las ciudades la gran mayoría de las personas (plebeyos incluidos) serían capaces de entenderlo, por lo cual se justificaría una predicación en esa lengua.

\section{Referencias citadas}

Agustí, A. (1993): “Els concilis de la Tarraconense. Algunes aportacions a la història de la llengua catalana", en J. Carbonell, ed., Estudis de llengua i literatura catalanes, XXVII, Barcelona, Publicacions de l'Abadia de Montserrat, pp. 53-94.

Agustí, A. (1994): Llengua i Església a la Lleida del XVI al XVIII, Lleida, Universitat de Lleida.

Bada, J. (1982): "Origen dels bisbes de les seus catalanes (1500-1982), Qüestions de vida cristiana, 113, pp. 102-110.

Badia i Margarit, A. (1999): Les Regles de esquivar vocables $i$ „la qüestió de la llengua“, Barcelona, Institut d'Estudis Catalans.

Baggioni, D. (1997): Langues et nations en Europe, Paris, Éditions Payot \& Rivages. 
Baró i Queralt, X. (2009): La historiografia catalana en el segle del barroc (1585-1709), Barcelona, Publicacions de l'Abadia de Montserrat.

Belenguer, E. (2001): La Corona de Argón en la monarquía hispánica. Del apogeo del siglo XV a la crisis del XVII, Barcelona, Ediciones Península.

Betrán, J. y Blanco Fernández, C. (2012): “Impresos jesuitas en la Cataluña moderna”, en J. Martínez Millán, H. Pizarro Llorente y E. Jiménez Pablo, eds., Los jesuitas. Religión, política y educación (siglos XVIXVII), Madrid, Unión de Editoriales Universitarias Españolas, pp. 557-585.

Beuter, A. (1546): Primera parte de la Coronica general de toda España y especialmente del reyno de Valencia, Valencia, Joan de Mey.

Burke, P. (2006): Wörter machen Leute. Gesellschaft und Sprachen im Europa der Frühen Neuzeit, Berlin, Verlag Klaus Wagenbach.

Busquets i Dalmau, J. (1994): La Catalunya del barroc vista des de Girona: la Crònica de Jeroni de Real (16261683), vol. I, Barcelona, Publicacions de l'Abadia de Montserrat.

Canalda i Llobet, S. y Fontcuberta i Famadas, C. (2012): "Lengua, identidade y religión en el arte catalán de los siglos XVI a XVIII", Renaessanceforum, 8, pp. 205-230.

Carbonell, J. (1979): “Elements d'història social i política de la llengua catalana”, Treballs de sociolingüística catalana, 2, pp. 87-102.

Cardim, P. et al (eds.) (2012): Policentric monarchies.
How did Early Modern Spain and Portugal achieve and maintain a global hegemony?, Eastbourne, Sussex Academic Press.

Cardim, P. y J. Palos (eds.), (2012): El mundo de los virreyes en las monarquías de España y Portugal, Madrid, Iberoamericana.

Cisteller, D. (1636): Memorial en defensa de la lengua catalana para que se predique en ella en Cataluña, Tarragona, Gabriel Roberto.

Elliott, J.H. (1992): "A Europe of composite monarchies", Past and Present, 137, pp. 48-71.

Escolano, G. (1610): Década primera de la historia de la insigne, y coronada ciudad y reyno de Valencia, Valencia, Patricio Mey.

Fernández Cañueto, D. (2016): La Iglesia Católica y la nacionalización de Cataluña, Lleida, Edicions de la Universitat de Lleida, 2016.

Fernández Terricabras, I. (2010): “Una institución singular: los concilios provinciales de Tarragona en la Edad Moderna", Tiempos Modernos, 20, pp. 1-16.

Fernández Terricabras, I. (2011): “La implantació de la Reforma catòlica a les terres de parla catalana (1563-1700). Un procés reeixit?”, Catalan Historical Review, 4, pp. 227-240.

Gloël, M. (2014): Monarquía imaginada, - Eine Untersuchung zu Vorstellungen von der Monarchie auf der Iberischen Halbinsel im 16. und 17. Jahrhundert, Hamburgo, Verlag Dr. Kovac. 
Gómez Adrín, J. Memorial en defensa de la lengua castellana, para que se predique en ella en Cataluña, lugar y año de impresión desconocidos.

Hurtado, J. et al. (1940): Historia de la literatura española, Tomo II, Madrid, Saeta.

López Madera, G. (1601): Discursos de la certidumbre de las reliquias descubiertas en Granada desde el año de 1588 hasta el de 1598, Granada, Sebastián de Mena.

Marfany, J.L. (2001): La llengua maltractada. El castellà i el català a la Catalunya del segle XV al segle XIX, Barcelona, Empúries.

Marfany, J. L. (2008): Llengua, nació i disglòssia, Barcelona, L'Avenç.

Mar-Molinero, C. (2000): “The Iberian Peninsula: conflicting linguistic nationalisms", en S. Barbour y C. Carmichael, eds., Language and nationalism in Europe, Oxford, Oxford University Press, pp. 83-104.

Martí de Viciana, R. (1574): Libro de alabanças de las lenguas hebrea, griega, latina, castellana yvalenciana, Valencia, Joan Navarro.

Milhou, A. (1995): “Les politiques de la langueà l'époque moderne. De l'Europe á l'Amérique", en Marie-Cécile Bénassy-Berling, J. Clément y A. Milhou, eds., Langues et cultures en Amérique espagnole coloniale, Paris, Centre de Recherche Interuniversitaire sur l'Amérique Espagnole Coloniale, pp. 15-40.

Mond, P. (1996): “Estado, nación y monarquía en el siglo XVIII: visión comparativa", en C. Russell y J. A. Gallego, eds., Las monarquías del antiguo régimen, ¿monarquías compuestas?, Madrid, Editorial Complutense, pp. 11-29.

Morgado García, A. (2007): "El clero en la España de los siglos XVI y XVII. Estado de la cuestión y últimas tendencias", Manuscrits, 25, pp. 75-100.

Nagore, F. (1977): Gramática de la lengua aragonesa, Zaragoza, Librería General.

Pas, A. (1579): Primera parte de los discursos espirituales sobre la inscripción, prólogo, y quatro primeros capítulos de la regla de los terceros, Barcelona, Pedro Malo.

Peña Díaz, M. (1997): “El castellano en la Cataluña de los siglos XVI y XVII", Manuscrits: Revista d'Història Moderna, 15, pp. 149-155.

Passola i Tejedor, A. (1986): "Una oligarquia municipal. La Paheria de Lleida em el s. XVII", Manuscrits: Revista d'Història Moderna, 3, pp. 151-173.

Passola i Tejedor, A. (2001): "La élite municipal leridana bajo los Austrias", Revista de Historia Moderna: Anales de la Universidad de Alicante, 19, pp. 269-312.

Pérez Samper, M. A. (1999): “La corte itinerante. Las visitas reales", en E. Belenguer Cebrià, ed., Felipe II y el mediterráneo. La monarquía y los reinos (I), Madrid, Sociedad Estatal para la Conmemoración de los Centenarios de Felipe II y Carlos V, pp. 115 - 142.

Pitarch, V. (2000): “Nota sobre la qüestió de la llengua al barroc: dues perspecives des de la talaia tortosina", en Institut d'Estudis Catalans, ed., Jornades de la Secció Filològica de l'IEC a Tortosa, Barcelona: Institut d'Estudis Catalans, pp. 49-59. 
Prats, M. (1995): Política lingüística de l’Església catalana, Girona, Eumo.

Ramis Barceló, R. (2018): Estudios sobre la Universidad de Lérida (1561-1717), Madrid, Universidad Carlos III.

Rivero Rodríguez, M. (2011): La edad de oro de los virreyes. El virreinato en la Monarquía Hispánica durante los siglos XVI y XVII, Madrid, Akal.

Rivero Rodríguez, M. (2017): La monarquía de los Austrias. Historia del imperio español, Madrid: Alianza.

Sabaté F. (ed.) (2017): The crown of Aragon: a singular Mediterranean empire, Leiden: Brill.

Simon i Tarrés, A. (1999): Els orígens ideològics de la revolució catalana de 1640, Barcelona, Publicacions de l'Abadia de Montserrat.

Simon i Tarrés, A. (2005): Construccions polítiques i identitats nacionals. Catalunya i els orígens de l'estat modern espanyol, Barcelona, Publicacions de l'Abadia de Montserrat.

Simon i Tarrés, A. (2016): Llengua i política a ña Catalunya del segle XVII. Alexandre Rosi Gomar (1604-1656), Barcelona, Editorial Afers.

Sousa de Macedo, A. (1631): Flores de España, excelencias de Portugal, Lisboa, Jorge Rodríguez.

Teruelo Núñez, M. S. (1987): “Bilingüismo literario en Portugal, en Universidad de Oviedo, ed., Homenaje a Álvaro Galmés de Fuentes, tomo I, Madrid, Editorial Gredos, pp. 317-334.
Torrent, A.M.(1989): “Llenguaipoder polític a Catalunya al segle XVII", en A. Badia i Margarit y M. Camprubí, eds., Actes del Vuité Col-loqui Internacional de Llengua i Literatura Catalanes /II, Barcelona, Publicacions de l'Abadia de Montserrat, pp. 29-55.

Torres Sans, X. (2008): Naciones sin nacionalismo. Cataluña en la Monarquía Hispánica (siglos XVI-XVII), Valencia, Universitat de València.

Vila Despujol, I. (2012): “La Compañía de Jesús y los virreyes de Cataluña (S. XVI y XVII)”, en J. Martínez Millán, H. Pizarro Llorente y E. Jiménez Pablo, eds., Los jesuitas. Religión, política y educación (siglos XVIXVII), Madrid, Unión de Editoriales Universitarias Españolas, pp. 207-230.

\section{Notas}

1 Se publica bajo el nombre de Juan Gómez Adrín pero hoy en día no cabe duda de que se trata de un seudónimo del jesuita Alexandre Ros. Por ello, hemos decidido usar su nombre verdadero en todo el texto.

2 Se citará por los estas publicaciones originales. Hay que señalar que ambos textos carecen de paginación.

3 El memorial íntegro está reproducido en Prats, 1995: 77-83.

4 Juan Gómez Adrín, Memorial en defensa de la lengua castellana, para que se predique en ella en Cataluña, lugar y año de impresión desconocidos. No hay paginación. Es de asumir, sin embargo, que se escribió en 1636 , por lo que usaremos tal año como referencia.

5 Dídac Cisteller, Memorial en defensa de la lengu 
catalana para que se predique en ella en Cataluña, Tarragona: Gabriel Roberto, 1636. No hay paginación.

6 En el caso de Burke, se trata de la traducción alemana del original inglés Languages and communities in early modern Europe, publicado en 2004. 